\title{
WHY UNIVERSITY RANKINGS DO NOT CHANGE: EDUCATION AS A NATURAL HIERARCHICAL FLOW ARCHITECTURE
}

\author{
ADRIAN BEJAN \\ Department of Mechanical Engineering and Materials Science, Duke University, Durham, NC, USA.
}

\section{ABSTRACT}

In this article we rely on constructal theory to show that the hierarchy of universities is rigid, and that the explanation lies in the nature of education (science, news, information) as a natural flow system that bathes the globe most effectively. The article begins with two observations: (i) the rankings of the best engineering universities in the USA closely mirror the rankings of the universities that have the most names of researchers on the list of the most highly cited authors; and (ii) the log-log plot of the number of highly cited authors of one school versus the rank of that school is nearly a straight line with slope between $-1 / 2$ and -1 . The straight line is the same as the distribution of city sizes versus city rank throughout the history of Europe. From this follows the argument that the hierarchy of universities is tied to geography, to how each nodule of knowledge generation serves the area allocated to it. Education flows from point to area. The compounding of areas to cover the landscape is the origin of the hierarchical and stable arrangement of universities. The rank of a university is closely related to the visibility of its producers of ideas. The tapestry of a university on the landscape is predicted. All universities grow and improve in time (like all the river channels during the rain), but their hierarchy remains the same.

Keywords: academic visibility, constructal law, education, information flow, news propagation, science evolution, university rankings.

\section{THE OBSERVED PATTERN: UNIVERSITY RANKINGS DO NOT CHANGE}

Each new release of the rankings of America's best universities [1] is an invitation to theory. As usual, the rankings are the talk of the campus. Some administrators discount the importance of rankings, while the rest declare that the university is finally (now) poised to execute 'the great leap forward'.

This two-sided reaction has not changed in ten years. Why? Because the rankings themselves have not changed in any meaningful way in ten years.

A pattern that persists in time by resisting big forces (expenditures) to change, speaks of the much bigger forces of nature. It speaks of physics and the design of nature, in this case the design of social dynamics. Natural patterns are demanding to be predicted and to be moved from the side of the unexplained to the side of the explained. This article makes two contributions in this direction: (i) the formulation of the question of why university rankings do not change and (ii) an answer based on constructal theory.

\section{CONSTRUCTAL THEORY OF 'DESIGNEDNESS' IN NATURE}

Constructal theory is the view that the generation of designedness in nature is a phenomenon of all physics, i.e. of everything, animate or inanimate, or biological, geophysical and societal. According to constructal theory, this phenomenon can be reasoned on the basis of one principle: designs persist in time by changing into configurations that offer progressively better access to the currents that flow through the territories bathed by the patterns. This principle of generation of flow configuration in time (in the sense of an animated movie, in a certain direction) is the constructal law of 1996 [2, 3]:

For a finite-size flow system to persist in time (to live) its configuration must change such that it provides easier access to its streams. 
During the past decade, constructal theory has successfully predicted the occurrence of natural patterns across the board, from geophysics to biology and social organization [4-12]. Examples are the design (scaling laws) of river basins [7]; the diverse morphologies of stony corals, bacterial colonies, and plant roots [9]; and the speeds, frequencies, and forces of all animal locomotion (running, flying, swimming) [10]. Constructal theory has shown that a single principle can be used to predict all the other designs that in the past have been based on ad-hoc and often contradictory postulates of optimality ( $\min , \max$ ), e.g. minimization of entropy generation in engineering, maximization ( $\mathrm{sic}$ ) of entropy generation in geophysics, maximization of 'fitness' and 'adaptability' in biology, minimization of 'energy' (i.e. food) in biology, minimization of travel time in optics and urban traffic, minimization of flow resistance in river mechanics, maximization ( $\mathrm{sic}$ ) of resistance in biology and engineering (e.g. thermal insulation, walls of ducts that do not leak), and the axiom of uniform maximal stresses in the design of natural solid structures (bones, trees). This growing body of work has been reviewed most recently in [4-6, 8, 12].

The élan that constructal theory has generated in science [8] is so contagious, and the theory itself so common sense, concise, and useful, that it deserves to be discussed more broadly with colleagues from totally unsuspecting fields. Constructal theory has attracted an international community of physicists and social scientists who view social organization deterministically as a conglomerate of mating flows that morph in time to flow more easily (e.g. goods, people, energy, information). The work of this community forms the subject of a new book [11]. Societal flow architectures have direction of morphing (e.g. minimization of expenditure of useful energy (exergy, fuel, food) travel time, cost), and the objectives clash with global constraints (territory, time, resources). Once again, the result is the generation of flow architecture, which is a physics phenomenon that is reasoned on the basis of a principle of configuration evolution in time: the constructal law.

Society is a 'live' flow system, perhaps the most complex and puzzling we know. It is a jungle of flow systems - a vast multiscale system of systems - with organization (design), hierarchies, and time direction of morphing (evolution). It is the most difficult to comprehend because we, the minds that try to make sense of it, are small and deep inside the flow system. Difficult because each of us is like an alveolus in the lung, an eddy in a turbulent river, or a vein on a leaf on a tree branch. From such a position of nothingness, which is identical in rank to the positions of enormous numbers of individuals, it is a formidable task to see and describe the big picture - the lung, the river basin, and the forest.

Man's great fortune has been the fact that nature has shape, structure, configuration, pattern, rhythm, and similarity. From this stroke of luck, science was born and developed to the present day, where it is responsible for our well-being. The puzzling architecture and history of society has everything in common with the evolution of other complex (but simpler) flow architectures: river basins and deltas, turbulence, blood vascularization, animal movement, respiration, dendritic solidification, etc. Coincidences that occur in enormous numbers are loud hints that a universal principle is in play. This principle accounts for a broad array of 'pattern generation' phenomena in geography, demography, communications, hierarchy, and multiple scales. Examples are the multiscale distribution of living settlements, the occurrence of structure inside each settlement, 'development' as a relation between fast flowing societies and advancement, wealth, migration patterns, and globalization.

In sum, this new direction places the occurrence of social organization on a physics basis. It brings social organization under the same physics principle that accounts for the generation of flow architecture (design) in geophysical flows and animal design and movement. It adds a dose of determinism to the modeling and predicting of social flows.

To think about the rigidity of university rankings in terms of constructal theory, we must have an understanding of the flow system - what territory it covers and what currents flow through it. We develop this view gradually, by asking additional questions. 


\section{WHAT OTHER PATTERNS DO NOT CHANGE?}

The academic world did not need magazines (U.S. News, The Times) and Shanghai Jiaotong University to have a feeling for rankings. Every student who enters a university has a view of which universities are better, and wishes to be in the best. A postulating professor thinks the same way. These are very large numbers of individuals wanting the same thing: to be in the best channels of societal flow. Admittedly, their numbers are not as big as the number of droplets of water in a river basin, but their urge is the same: to go with the flow, to be in channels that provide greater access.

Long before the magazines, the university world had a good feeling for rankings, because people in academia understand one concept very well: fame. 'Name' matters, from the Universities of Bologna (Alma Mater Studiorum) and Padova to the Sorbonne, Oxford, Cambridge, Coimbra, and Harvard. Fame is why the publication of an idea begins with the author's name and the date of publication. Fame, or visibility, is synonymous with greater access through the vascular structure of societal flows.

\section{HOW DOES ONE MEASURE FAME?}

An author and a university become known because of the ideas they generate. Good ideas travel and persist (to 'persist' means to keep on traveling, flowing, from those who know to those who need to know). The good ideas are the ideas that are adopted by others, worldwide. Inferior ideas are replaced and forgotten - most, like most of the published research papers, are not even noticed.

The least biased measure of academic visibility available today is the number of citations of an author's creative output. Such statistics are provided by the Institute of Scientific Information. The simplest and most relevant facsimile is the list of the most cited research authors [13]. It is an unbiased sample because the researchers who cite an author's work do so because they read it, they valued it, and they used it. These numerous voters are genuine. They are not recommended by anybody. They are not hand-picked by a magazine. They do not belong to a club. The best part is that one can see who they are and why they cited the author.

The most-cited listing is a sample of perfect size for this discussion because among the 250 names listed for all 'engineering' (all engineering disciplines, all countries, living or deceased) there are 137 names from US engineering schools. For each US graduate engineering school ranked in the top 50 by U.S. News [1], I counted the number of names that appear on the most-cited list [13]. I plotted this number on the ordinate in Fig. 1. The abscissa indicates the ranking in U.S. News.

Figure 1 provides a bird's eye view of where university rankings come from. The highly ranked engineering schools are homes to researchers who are highly visible. The lowly ranked schools are not. The left end of the scale is dominated by schools with ordinates in the 5-10 range. The right end is dominated by schools with 0 on the ordinate.

This is not a chicken and egg argument. The direction is one way. The university rankings come from the highly cited, not the other way around. An author is highly cited because the author is creative, not because of the name of the author's employer. (One of the reviewers of the original manuscript argued that the other direction also functions, because the name of the employer attracts the creative, i.e. it attracts fame. No. This tendency of organization is the phenomenon already noted at the start of Section 3. The reason we use and cite an article is the idea that the article conveys. In my own field, we cite Prandtl all the time because of boundary layer theory, not because of the fame of Göttingen. Of course, users have memory, and they get better by training. When they observe that articles by author $Z$ tend to contain useful ideas (or even useful words, phrases, and drawings worth copying), then they look for future or forgotten articles by author $Z$. When, generation after generation, users observe that authors of type $\mathrm{Z}$ tend to reside in universities of the type where author $\mathrm{Z}$ works, the users learn and behave as noted at the start of Section 3.) 


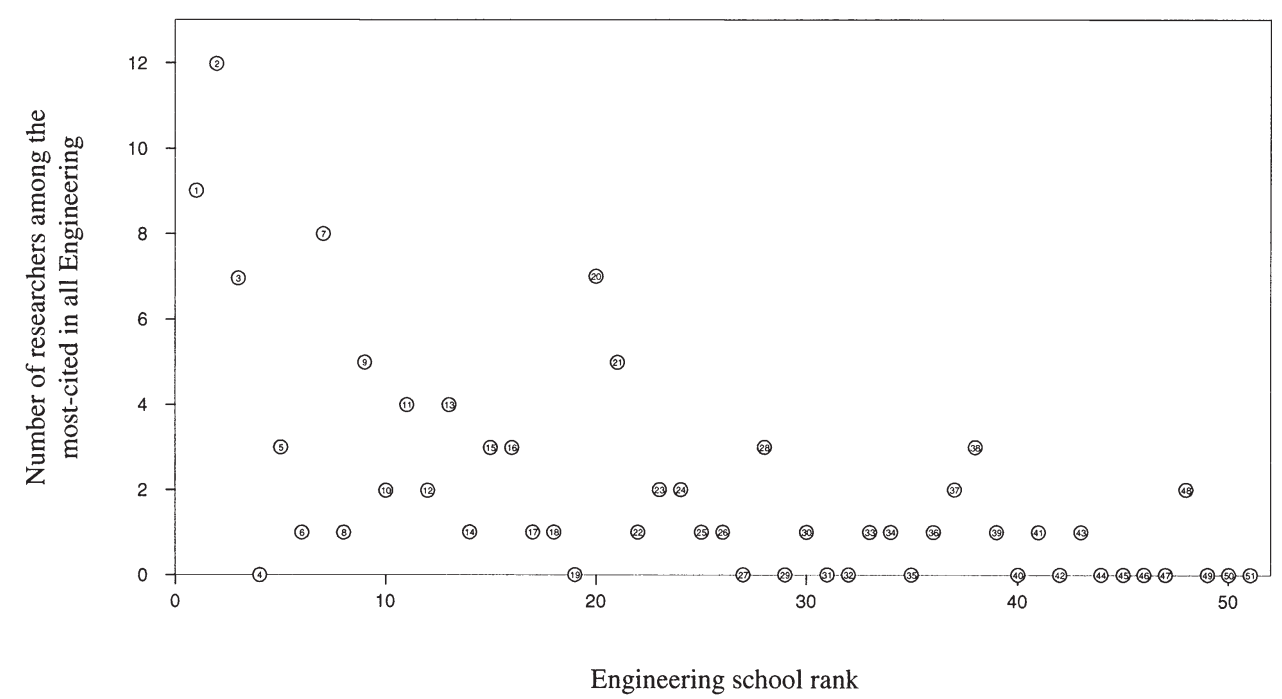

Figure 1: Fame versus rank: the number of most-cited researchers in each top US engineering school versus the rank of the engineering school [1].

The scatter in Fig. 1 does not diminish the firmness of this conclusion. One can argue that 'size matters', which is why some highly ranked schools (with 4 and 19 on the abscissa, for example) have 0 on the ordinate. These examples are the exception, not the rule. To stress this, I replotted the points of Fig. 1 by scribing the same values on the ordinate, and using a new abscissa: the rank of the particular school on the list of the most-cited in all engineering. The result is Fig. 2. For example, rank 1 on the abscissa of Fig. 2 belongs to the school with the most names on the most-cited list (that school was ranked 2 on the abscissa in Fig. 1). Because of the logarithmic ordinate in Fig. 2, the points with 0 on the ordinate are not shown.

In the new representation of Fig. 2, the points descend smoothly from left to right. Practically, all the points that were on the left in Fig. 1 are still on the left in Fig. 2. Immobility also characterizes the points on the right in Figs 1 and 2. The 30-32 abscissa range of Fig. 1 is essentially the same as the $25-40$ range of Fig. 2.

\section{WHY ARE THE HIGHLY RANKED FEW AND THE LOWLY RANKED MANY?}

Figures 1 and 2 show that the ranking of universities is hierarchical, like the airways of the lung, the channels of the river basin, and the cities of a country or continent. The more highly ranked, the fewer the competitors for the high positions. The trachea, the Danube River, and Paris are not to be confused with the other airways, river channels, and human settlements. The opposite is true in the other direction: the lower the rank, the more numerous the candidates that compete for that rank. Why?

The clue lies in the nearly straight line that the data form on the log-log plot in Fig. 2. This line has a slope between $-1 / 2$ and -1 , and is coincidentally the same as the distributions of city sizes throughout the modern history of Europe [12, 14] (Fig. 3). The similarity between Figs 2 and 3 suggests that the distributions of sources of knowledge is intimately tied to geography (flows on the landscape), to the tissue of information channels on the surface of the globe.

Here is how to use flow geography to predict the linear trend visible in Fig. 2 (the same trend would appear fuzzier but still linear if Fig. 1 were replotted in log-log coordinates). Imagine an area 


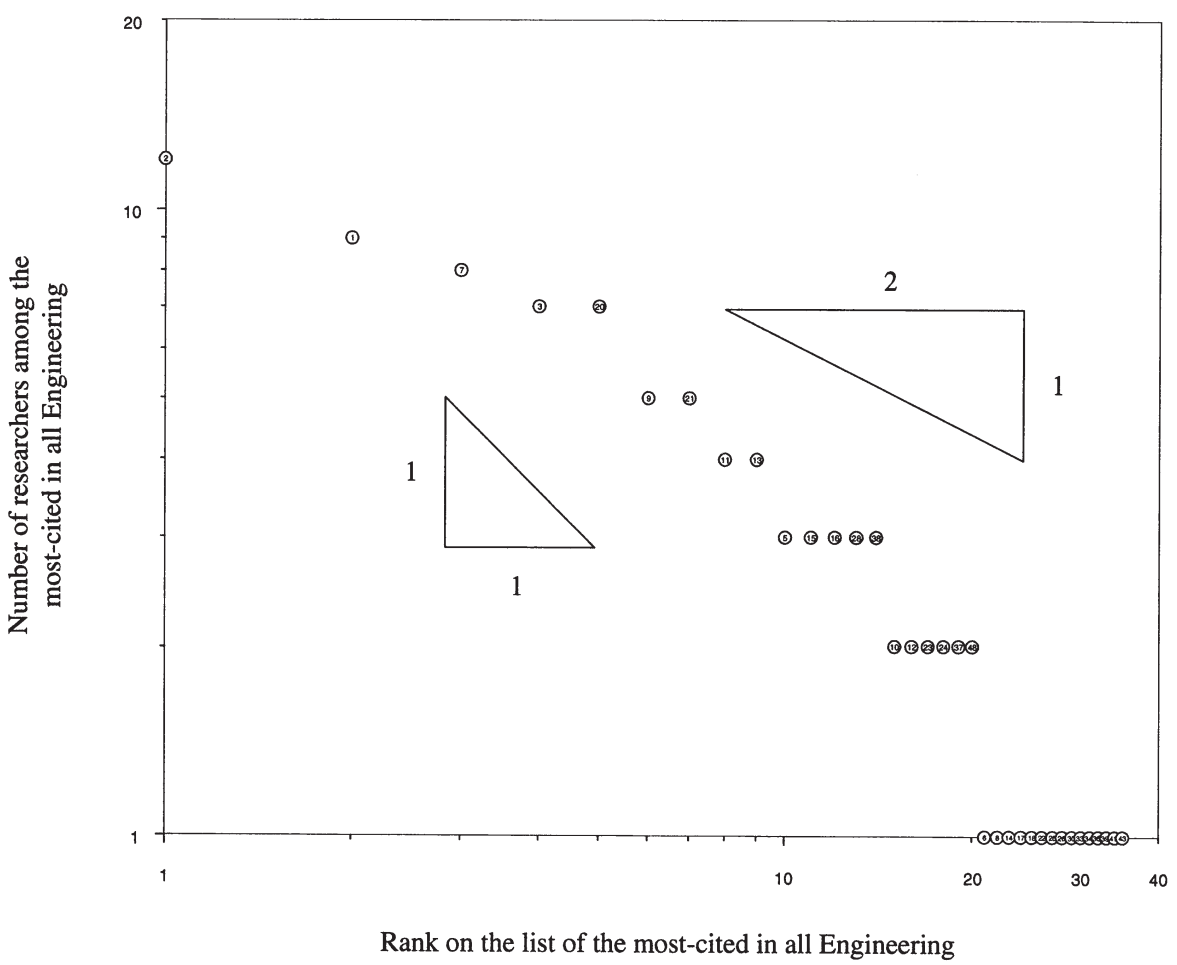

Figure 2: The number of most-cited researchers in each top US engineering school versus the rank of that school on the most-cited list (based on data from [13]).

element $A_{1}$ the inhabitants of which number $N_{1}$ and live on $A_{1}$. The inhabitants produce things (students, agricultural products, timber, game, minerals, etc.) the flow rates of which are proportional to $A_{1}$. These flow rates sustain a human settlement (a concentration) located on $A_{1}$, where the number of inhabitants is $N_{1}$ and the production is of a different sort (education, knowledge, services, devices). There is an equilibrium between what flows from the area $A_{1}$ to the human concentration $N_{1}$, and what flows from $N_{1}$ to $A_{1}$. The 'key' idea is that both classes of flow rates (area-point and point-area) are proportional to $A_{1}$, and this means that the size of the human settlement $N_{1}$ is proportional to $A_{1}$.

One type of service that flows from the human concentration $N_{1}$ to the humanity spread over $A_{1}$ is education, educated individuals, books, knowledge, and science. The human settlement in this case is the university, and the area $A_{1}$ is the territory that the university serves. The constellation of universities on the landscape is a reflection of the area constructs of land-city counterflows that cover the globe.

Constructal theory showed earlier [2] that if the tendency is toward maximum access (minimum travel time) then the distribution of humans on the earth's surface can be viewed as a construction of compounding area constructs, as shown schematically at the top of Fig. 4. Like an area element in a river basin, which feeds the big stream that leaves the area, each area construct sustains the flows that reach a human concentration on the boundary of the construct. It follows that the human concentration on the boundary is proportional to the size of the construct. If the human concentration represents the university, then the university (flow of ideas, impact) is proportional to the size of the area 


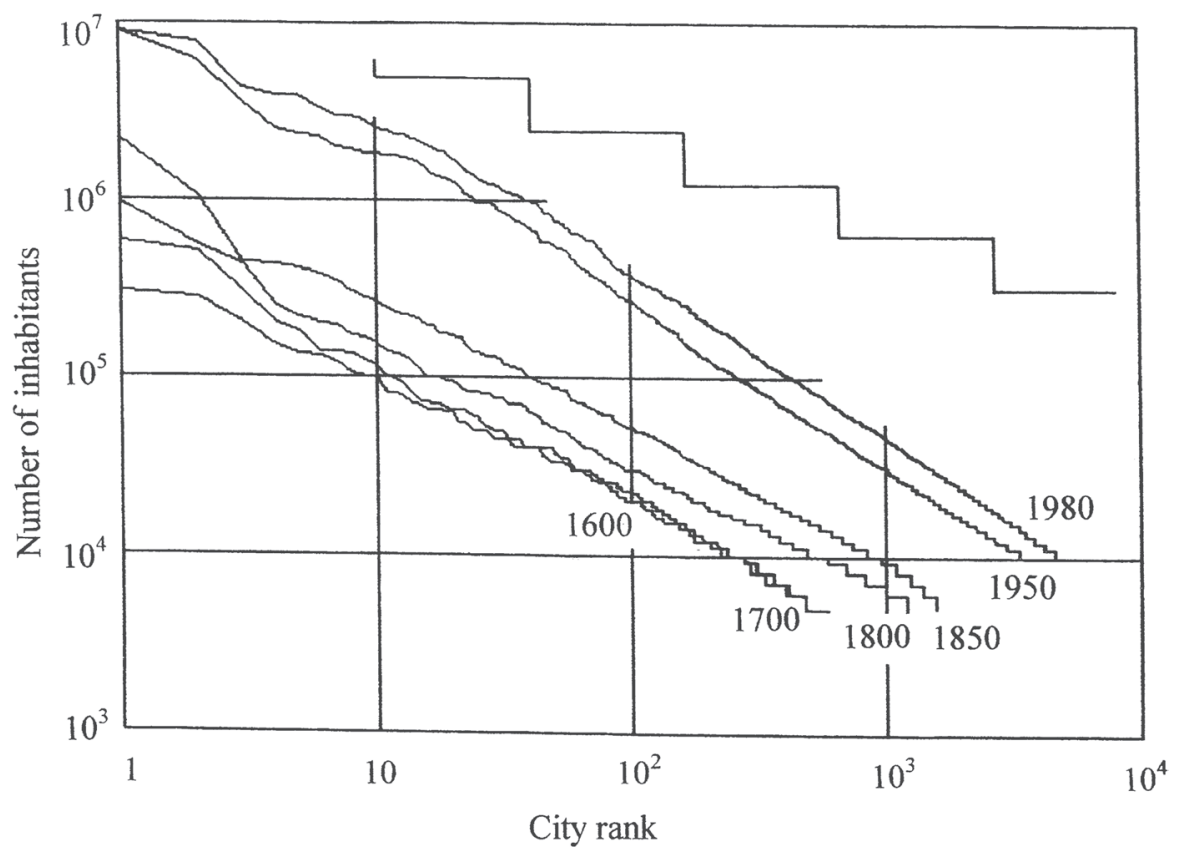

Figure 3: The ranking of European cities according to size throughout modern history [12, 14].

construct that it serves. The landscape is covered by universities ranked hierarchically because the area constructs have multiple sizes and are assembled hierarchically.

The construction sequence sketched in Fig. 4 is based on area doubling. The rank of the university sustained by the area construct doubles in going from small area to large area. This construction is how we discover theoretically the pattern hidden in the present-day rankings. (This construction is not a 'time sequence' in which the landscape might have been covered by the tapestry of knowledge in history.) The construction is sketched in the bottom left of Fig. 4, where the size of the black dot is meant to indicate the rank, i.e. the flow rate of knowledge that the human settlement generates. Given an area, the top ranked university serves not only the area but also the lesser ranked universities that are spread on that area.

The bottom right of Fig. 4 shows the distribution of multirank universities on the landscape after deleting the construction lines used earlier. The hierarchy of ranks is evident: one top university, two universities tied for places 2 and 3, four universities tied for places 4-7, etc. This pattern is discovered here based on pure theory (the maximization of access in area-point flow), and is represented by the stepped line drawn in Fig. 4. The slope of this line is $-1 / 2$, in acceptable agreement with what we saw in Fig. 2. The important conclusion is not the predicted slope but the fact that the straight line has its origin in the maximization of area-point access for the flow of information between many inhabitants who live on the same landscape.

\section{WHY IS HIERARCHY RIGID?}

The short answer is that ideas, science and education, flow on the globe like water in a river basin. They flow through a hierarchical network of multiscale channels, which provide maximum flow access for all the information that flows, for the entire territory. 

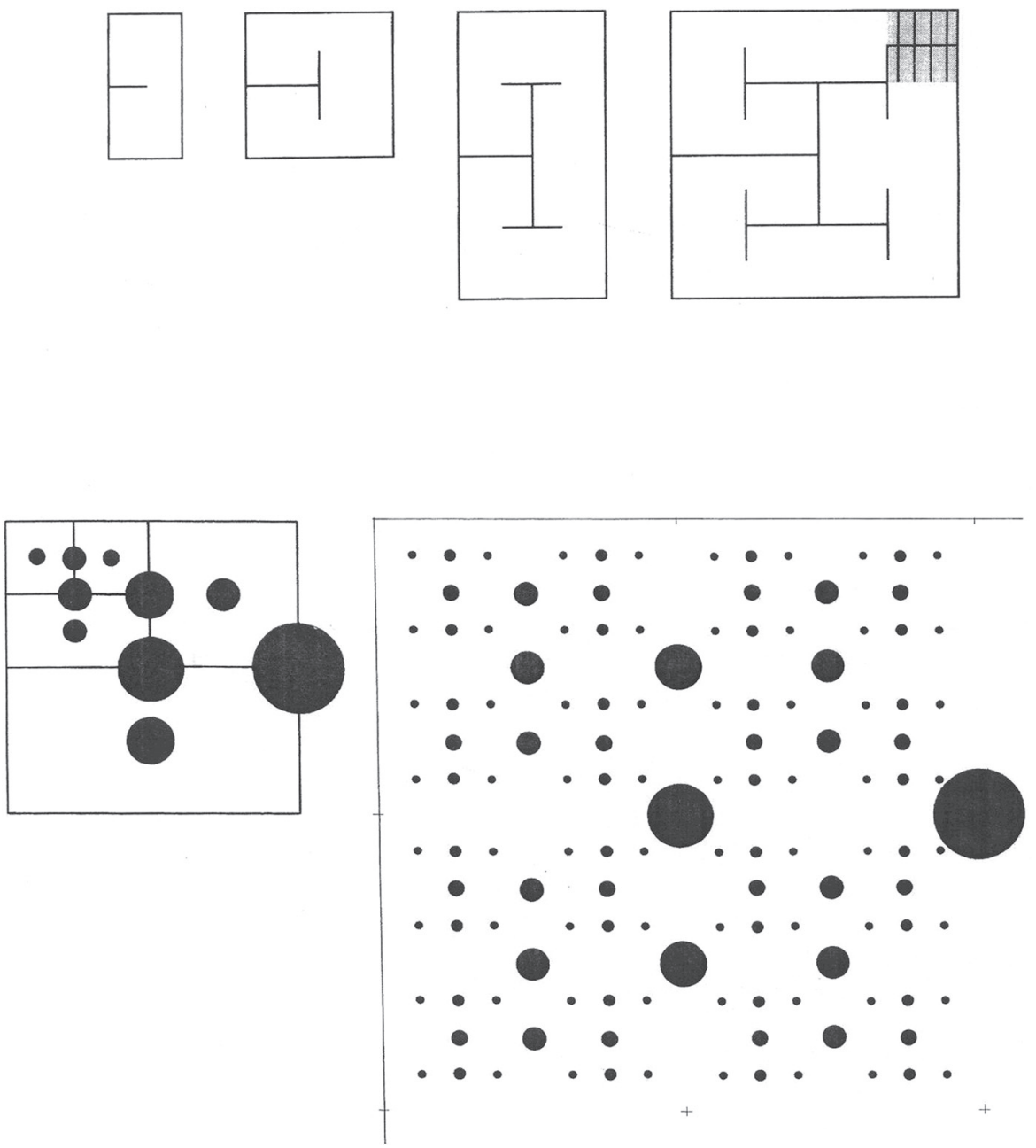

Figure 4: The landscape of multi-rank universities as a tapestry of hierarchically assembled areas.

When numerous researchers value and use an author's work, the idea flows from the author to the user. It flows 'well', because of the long history and entrenched geography of the flow network, which is due to the evolutionary process that brought the whole world of science-sharing to the present level of effectiveness. The success of this evolutionary process goes unnoticed. It is the reason why the user from one end of the globe actually looks for, finds, and trusts the ideas and young professors produced by a famed university or professor located at the other end of the globe.

There are many intermediary channels along each route: other universities, disciples of known professors, journals, libraries, etc. The intermediaries have evolved into a hierarchical flow structure the right sizes, put in the right places. Each route is a tree-shaped point-to-area flow, from one source to the entire globe, or a tree-shaped area-to-point flow, from the entire globe to the famed source (the source maintains its rank by attracting students and disciples from the world).

These hierarchical flow designs serve everybody well. They are much older and more perfect (polished) than a new design that someone may promise to put in place today. The highly ranked and 
the lowly ranked go together. The flow of science improves in time because each school improves while maintaining the place that it has earned in the global structure.

The university administrator who hopes to change the rank of his university by simply stealing one top name from a highly ranked school is defeated by nature, every time. The same fate awaits the one who promises to change rankings by building something artificially big - artificial, because it is not demanded by the natural evolutionary history and geography that created our world academic weave. Such wishes are analogous to damming, blocking, or digging river channels. The artificial features of the flow network require constant maintenance (spending), more when the artificial does not resemble the natural. In the end, the water knows how and where to flow, the dams break, the dug channels dry up, and the natural design wins.

Is there a way to change rankings? It takes time, but there is a way, and the river basin provides the perfect metaphor for it. Cataclysmic change (e.g. plate tectonics) in the landscape of flow access is the answer. Likewise, the flow of higher education can be diverted through major changes in the loci of generation of new ideas and channels for the flow of information.

Freedom is good for design. We have seen this many times in the evolution of the flow of knowledge, from the movement of Leonardo da Vinci from sponsor to sponsor, to the abrupt transformation of nobodies into famous research universities in the USA right after World War II and right after Sputnik. Then, the cataclysmic change was the freedom that attracted the brain drain from post-war Europe, and, after Sputnik, the enormous jump in funding for basic ideas (i.e. basic science).

These changes had the effect of instituting a marketplace where the flow of ideas was more free. Not a richer one, not a bigger one, and certainly not one that was to be used as a generator of profit (overhead) for ancillary projects on campus. No. The way to create true academia on a plot of dirt was by putting up a table of ideas, like free food for the hungry. And the truly creative came, to create.

University $\mathrm{X}$ is not the piece of land in a particular spot on the map. It is the entire world map. It is the highly complex global tree-shaped flow network with University $\mathrm{X}$ as the central node, heart, and aorta. The same is true of all other universities.

The university is the professors, their disciples, and the disciples' disciples. It is the ideas that flow through these human links and into the books of our evolving (morphing) science and culture. In time, this global vasculature evolves like a river basin during the rainy season: all the streams swell, but their hierarchy remains the same.

\section{REFERENCES}

[1] U.S. News \& World Report, America's best graduate schools: schools of engineering, p. 89, 9 April 2007.

[2] Bejan, A., Advanced Engineering Thermodynamics, 2nd edn, Wiley: New York, 1997.

[3] Bejan, A., Shape and Structure, from Engineering to Nature, Cambridge University Press: Cambridge, UK, 2000.

[4] Bejan, A. \& Lorente, S., Constructal theory of generation of configuration in nature and engineering. J. Appl. Phys., 100, 041301, 2006.

[5] Reis, A.H., Constructal theory: from engineering to physics, and how flow systems develop shape and structure. Appl. Mech. Rev., 59, pp. 269-282, 2006.

[6] Poirier, H., A theory explains the intelligence of nature. Science \& Vie, 1034, pp. 44-63, 2003.

[7] Reis, A.H., Constructal view of scaling laws of river basins. Geomorphology, 78, pp. 201-206, 2006.

[8] Constructal Theory Web Portal, www.constructal.org. 
[9] Miguel, A.F., Constructal pattern formation in stony corals, bacterial colonies and plant roots under different hydrodynamics conditions. J. Theor. Biol., 242, pp. 954-961, 2006.

[10] Bejan, A. \& Marden, J.H., Constructing animal locomotion from new thermodynamics theory. American Scientist, 94, pp. 342-349, 2006.

[11] Bejan, A. \& Merkx, G.W. (eds), Constructal Theory of Social Dynamics, Springer: New York, 2007.

[12] Bejan, A., Advanced Engineering Thermodynamics, 3rd edn, Wiley: Hoboken, 2006.

[13] ISIHighlyCited.com, www.isihighlycited.com

[14] Bretagnolle, A., Mathian, H., Pumain, D. \& Rozenblat, C., Long-term dynamics of European towns and cities: towards a spatial model of urban growth. Cybergeo, article 131, 2000. 